\title{
Coordination In Hubei Province Economic Development And Environment
}

\author{
Guo Rui1 \\ 1School of Resources and Environmental Science and \\ Engineering, Hubei University of Science and \\ Technology, Xianning, China
}

\author{
Hao Hanzhou*1,2 \\ 1School of Resources and Environmental Science and \\ Engineering, Hubei University of Science and \\ Technology, Xianning, China \\ 2Land and Water Resources Research Center of the \\ Middle Yangtze River, Xianning, China \\ * Corresponding Author
}

\begin{abstract}
Based on the "Hubei Provincial Statistical Yearbook" in 1990 - in 2013 the relevant data to do statistical analysis, using DPS software gray correlation analysis and Kuznets curve (Kuznets curve) in support of SPSS software analysis to Hubei Hubei Province, in recent years, economic development and resources and the environment in Hubei Province into the relevance and coordination of research. Studies show that: (1) environmental pollution in Hubei Province showed significant decline, in 1990 the highest integrated pollution index, reached 1.39 in 1990 - between 1998, the pollution index volatility declined from 1998 until today, pollution index continues to decline, and decline significantly, namely resources and environment quality showed signs of improvement. (2) The correlation between resources and the environment and GDP per capita in Hubei Province show that: the greatest contribution to the solid waste, followed by the dust, once again it is waste water, followed by $\mathrm{SO}_{2}$, influence is the lightest gas. (3) Kuznets curve analysis showed $\mathrm{Zi}$ Nieci curve inverted " $U$ " type there is the right part, that standardization pollution index as per capita GDP growth gradually reduced, in other words, Hubei the comprehensive pollution index (CPI) should in the right half of the U-shaped curve.
\end{abstract}

Keywords-economic development; resources and environment; gray relational analysis; Kuznets curve; Hubei Province

\section{INTRODUCTION}

Since China's reform and opening, rapid economic development, resources and environment issues are emerging, however, environmental pollution and ecological damage caused huge economic losses[1]. China's economic growth is facing double-sided dilemma: natural resource constraints and pressure on energy saving[2].

In the study of the relationship between economic growth and environmental resources, the Environmental Kuznets Curve EKC (Environment Kuznets Curve) research hypothesis is the most common, study the internal mechanism of the formation of EKC can achieve economic development and coordination of resources and environment provide important theoretical basis[3]. EKC there is the internal mechanism of action of conversion of three different effects, they are: scale, technical effects and structural effects.

Based on the decoupling theory (Decoupling Theory) decoupling index, will be divided between economic growth and resource environment coupled relative decoupling, absolute decoupling three states [4]; Fang et al think coupling function urbanization and environment is the EKC curve and logic composite of the curve, thereby calculating the urbanization process of water resources constraint strength [5]; in addition Relational model and coupling degree model of gray correlation analysis to establish [6] and a structural equation model (Structural Equation Modeling, SEM) [7] it has also been used to study the relationship between urbanization and resource environment.

In Shaanxi Province, the application of entropy method and model of coordinated development of urbanization and its evolution trend coupling between resources and the environment, and build a comprehensive index system of urbanization and urban resources and the environment[8].Use of "decoupling" and "re-hook" theory, Cointegration and Granger causality test model, the empirical analysis of the coupling between urbanization and urban resources in Beijing between the pressure results show that: Beijing Urbanization and Urban Resource Stress overall "double growth" feature[9].

Between the environment and economic development resources, decoupling phenomenon explore the theory and practice is further deepened. Currently, many major domestic and foreign scholars on the definition of decoupling, the state of division and methods are discussed angles. First, from the definition of decoupling, the decoupling is mainly used reflect dependence between economic growth and material consumption changes[10]. Secondly, the state is divided from the point of view of decoupling, OECD countries have established a set based on the driving force - environmental pressures - the environmental state of the index system, analysis of decoupling economic development situation and material consumption and environmental pressure between the divided relative decoupling and absolute decoupling. Comprehensive Vehmas and Tapio and other scholars point of view, decoupling is further divided into strong decoupling, weak decoupling, the recession of decoupling, strong negative decoupling, decoupling weak negative, negative decoupling expansionary, growth link, degenerative link eight categories [11-13].

Based on this, the relevant data by Hubei economic development and resources and the environment in recent years, in order to support the DPS software and SPSS, 
from the perspective of the correlation with Kuznets curve on the coordination of economic development and resources and the environment in Hubei province were between research and analysis.

\section{DATA \& RESEARCH METHODS}

Data mainly from the "Statistical Yearbook of Hubei Province" in 1990 - 2013 data.

Data includes arable land per capita foundation area, the urban population and the proportion of urban population, total population, per capita GDP, the total amount of waste water, the total industrial emissions, total industrial chlorine dioxide emissions, total industrial soot emissions, industrial solid waste emissions and industrial dust emissions from waste.

(1) grey relational analysis by DPS software. Correlation is a measure of correlation between the size of the two systems or two factors, the correlation analysis of the core is to calculate correlation coefficients and correlation degree.

(2) In SPSS support, by means of factor analysis, building integrated pollution index.

Comprehensive pollution index (CPI) calculated by the following formula:

$$
C P I=\alpha_{1} F_{1}+\alpha_{2} F_{2}+\cdots+\alpha_{i} F_{i}
$$

$$
\text { Where, Fi is the } \mathrm{i} \text {-th factor score, } \alpha_{i}=\frac{\lambda_{i}}{\sum \lambda}
$$
variance contribution of the $\mathrm{i}$-th factor.

(3) EKC curve established. With the above calculation of the comprehensive pollution index (CPI) and per capita GDP, at SPPS software support, the establishment of nonlinear equations.

\section{RESULTS}

\section{A. the comprehensive pollution index (CPI)}

Pollution index decreased between 1-0.85 fluctuations. In 1990 - between 1992, the pollution index declined sharply from 1992 to 1995 , the pollution index rose rapidly, which means that pollution in Hubei Province unusually severe, but since 1995, until 1996, pollution index rapid decline, but in 1996 - In 1998, the pollution index increased again. Beginning in 1998, the pollution index continued to decline. The urbanization rate in constant slow growth of 29 percent from 1990 to 2013 of $55 \%$.

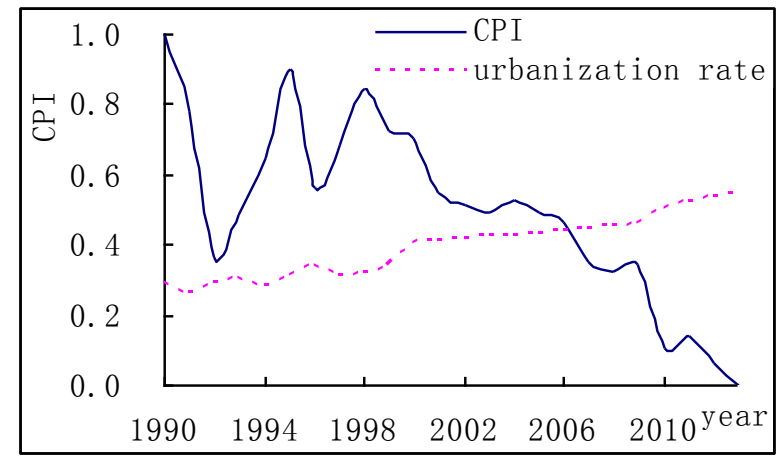

Figure 1. The integrated pollution index (CPI) and urbanization rate.

DPS software use, calculated gray correlation coefficient. In the table table 1: (1)correlation matrix displayed in GDP per capita terms, the correlation coefficient of per capita GDP and other contaminating factors in descending order are: exhaust gas $>\mathrm{SO}_{2}>$ wastewater $>$ dust $>$ soot $>$ solid waste, so that the exhaust gas and GDP per capita the highest correlation coefficient.

(2)correlation coefficient of exhaust gases and other pollution factors in descending order are: $\mathrm{SO}_{2}>$ dust> soot> solid waste, is the largest association of $\mathrm{SO}_{2}$.

(3) from the soot, the association of the largest $\mathrm{SO}_{2}$, and dust from the point of view, is the largest association of soot.

TABLE 1. CORRELATION MATRIX

\begin{tabular}{cccccccc}
\hline & $\mathrm{GDP}$ & $\mathrm{WW}^{\mathrm{a}}$ & $\mathrm{EG}^{\mathrm{b}}$ & $\mathrm{SO}_{2}$ & $\mathrm{Soot}$ & $\mathrm{SW}^{\mathrm{c}}$ & Dust \\
\hline $\mathrm{GDP}$ & 1.01 & 0.72 & 0.87 & 0.75 & 0.71 & 0.67 & 0.71 \\
$\mathrm{WW}$ & 0.68 & 1.01 & 0.73 & 0.85 & 0.88 & 0.74 & 0.82 \\
$\mathrm{EG}$ & 0.87 & 0.75 & 1.00 & 0.81 & 0.76 & 0.69 & 0.77 \\
$\mathrm{SO}_{2}$ & 0.73 & 0.86 & 0.81 & 1.01 & 0.87 & 0.71 & 0.87 \\
$\mathrm{Soot}$ & 0.69 & 0.89 & 0.75 & 0.87 & 1.00 & 0.76 & 0.89 \\
$\mathrm{SW}$ & 0.67 & 0.78 & 0.71 & 0.74 & 0.78 & 1.02 & 0.77 \\
Dust & 0.69 & 0.82 & 0.75 & 0.86 & 0.89 & 0.74 & 1.00 \\
\hline
\end{tabular}

a. Wastewater; b. Exhaust gas; c. Solid Waste

\section{B. EKC CURVE}

"Kuznets curve" (Kuznets curve), was in 1955 the famous American economist Kuznets proposed out of income distribution varies with the economic development process of the curve, income inequality to rise with economic growth after the drop, are important concepts in development economics.

According to the comprehensive pollution index and per capita GDP, can be EKC curve.

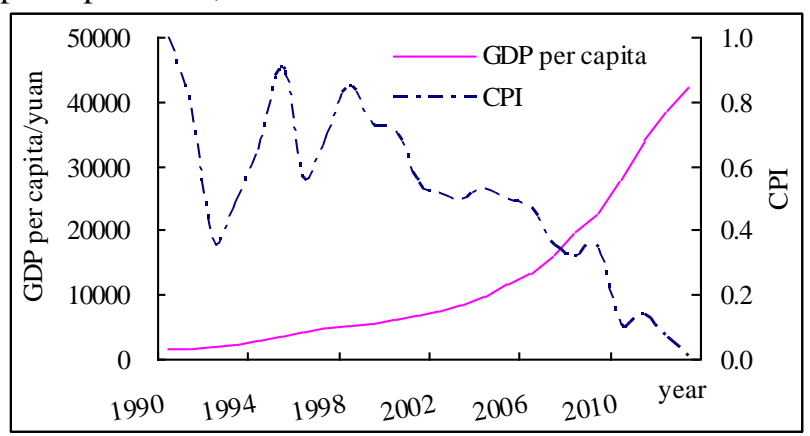

Figure 2. Per capita GDP and CPI. Changes in different years.

From Fig .2. it can be seen clearly from 1990 - 1998 period, with the increase of per capita GDP, environmental pollution levels rise and fall, but we can see the extent of pollution is quite serious, from 1998 - 2008 GDP per capita was slowly rising from 1,556 yuan to 5,287 yuan, while the pollution index is gradually decreased from 1 to 0.85 , indicating that environmental quality has been some improvement.

In order to more clearly observe the changes in per capita GDP between pollutants and extracting a 1990 -2013 per capita GDP and six pollution factor data, and per capita GDP for the $\mathrm{x}$-axis, respectively, in the six 
contamination factor (the total amount of wastewater discharge, total industrial emissions, total industrial chlorine dioxide emissions, total industrial soot emissions, industrial solid waste emissions and industrial dust emissions from waste) as $\mathrm{x}$-axis.

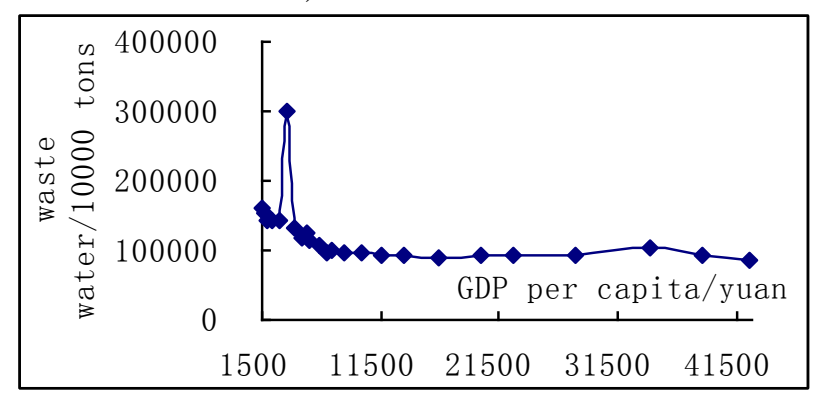

Per capita GDP and waste water.

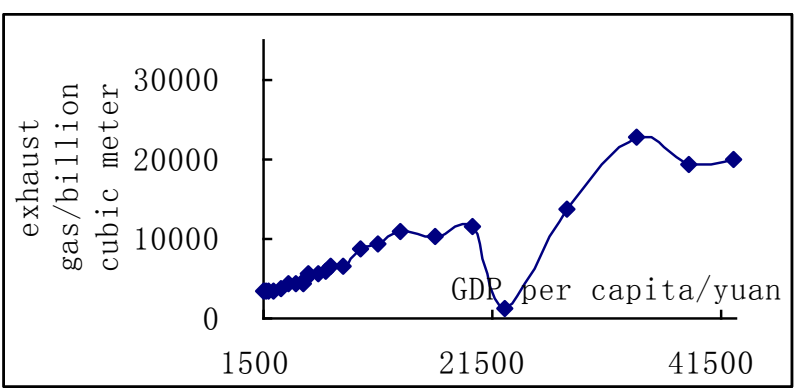

Per capita GDP and exhaust gas.

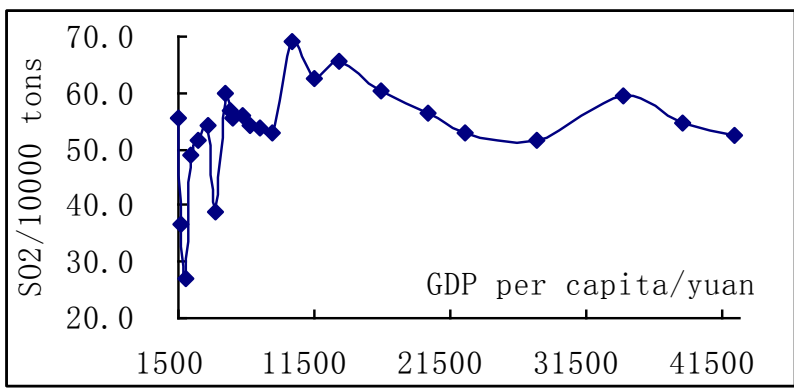

Per capita GDP and $\mathrm{SO}_{2}$

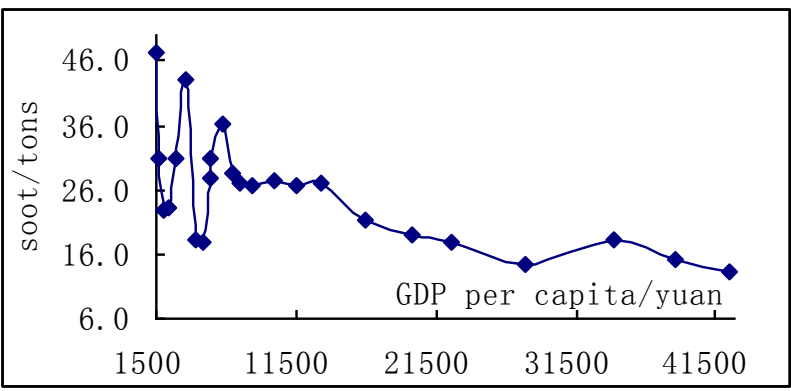

Per capita GDP and soot.

Before you begin to format your paper, first write and save the content as a separate text file. Keep your text and graphic files separate until after the text has been formatted and styled. Do not use hard tabs, and limit use of hard returns to only one return at the end of a paragraph. Do not add any kind of pagination anywhere in the paper. Do not number text heads-the template will do that for you.

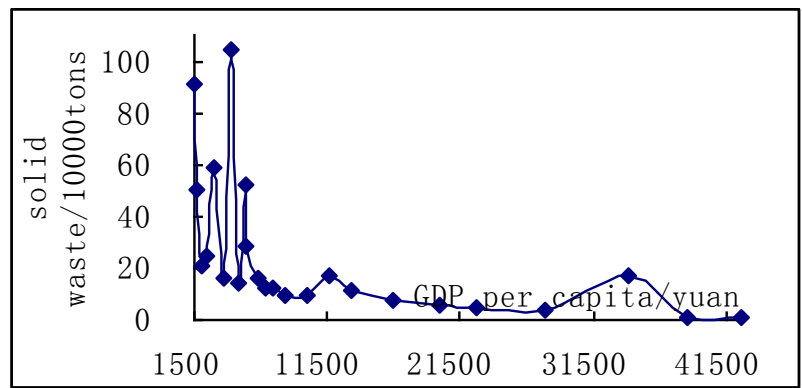

Per capita GDP and solid waste.

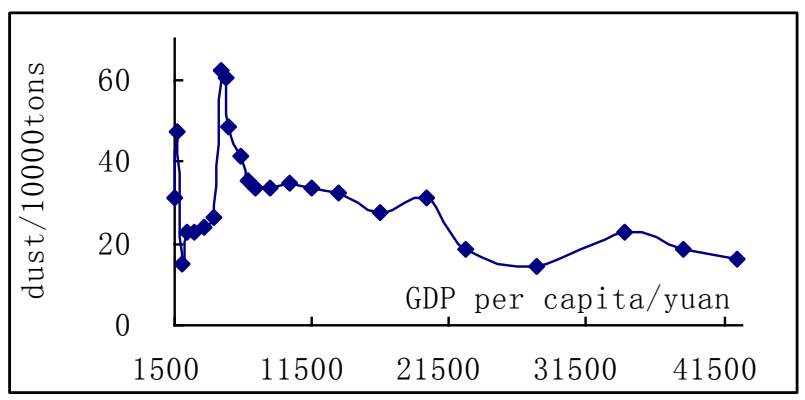

Per capita GDP and dust.

GDP per capita and integrated pollution index, constructed EKC curve.

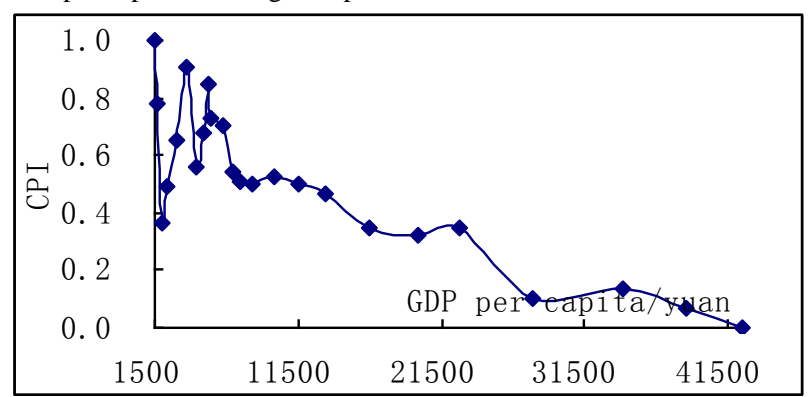

Per capita GDP and CPI.

Using the following "environmental Kuznets curve" model nonlinear fitting function using SPSS fitting ${ }^{[5]}$ :

$$
Z=m-n(x-p)^{2}
$$

Where, $\mathrm{Z}$ is comprehensive pollution index (CPI), $\mathrm{x}$ is GDP per capita, $m$ is environmental threshold. $n, p>0, m>$ $0, \mathrm{~m}$ represents the maximum pollution load.

By spss, a fitting equation is obtained:

$$
Z=1.273-4.61 \times 10^{-9}(x-17410.082)^{2}
$$

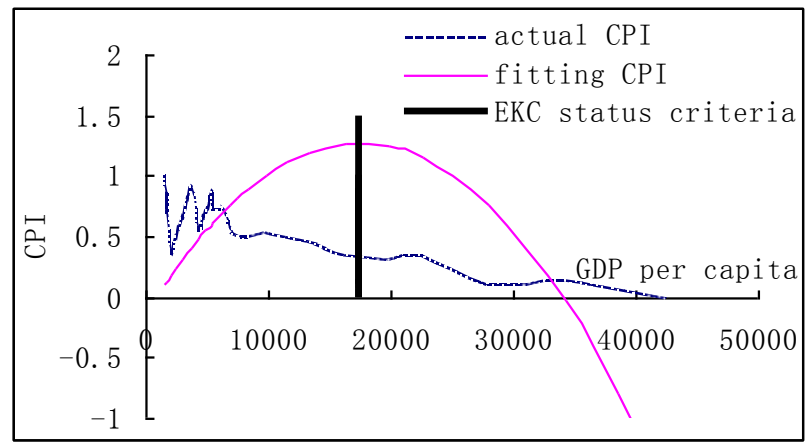

kuznets curve 
From the fitted equation can know, when per capita GDP> 17410.082, Hubei standardized API should be in the right part of the U-shaped curve.

Fig.10 is a Kuznets curve, showing the changes in standardized pollution index and GDP per capita, it can be found by looking at Figure 3.10, a standardized API with the growth of per capita GDP, with varying degrees of change, first down from 10.36 , then rose to 0.90 from 0.36 , then dropped to 0.56 from 0.9 , followed by another one to pick from 0.56 rose to 0.85 , and since then, standardized API with per capita GDP growth decreased. When the per capita GDP> 17410.082, the red trend line showing the downward trend, that is to say, Hubei standardized API should be in the right half of the U-shaped curve, which shows the economic development of Hubei Province has reached when 17410.082 yuan critical point, with the further development of the level of economic development per capita GDP, increased, then the degree of environmental pollution environmentally conscious people will gradually slow down, the environmental quality will gradually improve.

\section{CONCLUSIONS}

(1) Hubei integrated pollution index showed a downward trend. In 1990 - between 1992, the pollution index fell sharply. From 1992 to 1995, the pollution index rising rapidly. From 1998 until today, the pollution index declining.

(2) the correlation between economic development and resources and the environment. GDP closely associated with various pollution factors, the correlation coefficient of per capita GDP and other contaminating factors in descending order are: Exhaust $>\mathrm{SO}_{2}>$ Wastewater $>$ dust $>$ smoke> solid waste, therefore, with a correlation coefficient of per capita GDP, the highest exhaust gas, but also it means that the biggest impact on the environment of the exhaust gas, followed by the $\mathrm{SO}_{2}$

(3) On analysis of this paper, the Kuznets curve inverted " $U$ " type there is the right part, that standardization pollution index as per capita GDP growth gradually reduced, in other words, Hubei standardized API should in the right half of the U-shaped curve, which shows the economic development of Hubei Province has reached a critical point when 17410.082 yuan, with the further development of the level of economic development, per capita GDP, the People's awareness of environmental protection, natural environment pollution degree will gradually slow down, the environmental quality will gradually improve.

\section{MEASURES AND SUGGESTIONS}

Although coordination of the economic development and resources and the environment has been good improvement, but for the coordination of economic development and resources and the environment, the following suggestions proposed:

(1) Strengthen environmental protection and ecological construction, the rational allocation of urban resources, improve utilization and reuse of resources, outstanding resource-saving and environment-friendly concept of urban development.

(2) Achieve economic growth mode from extensive to intensive changes. A. reasonable adjustment of industrial structure, the optimization and upgrading of industrial structure; B. deepen economic reform.

(3)strive to rationalize the use of resources, legalization. Promote resource conservation, and into the legal system.

(4) Environmental protection to a strategic height.A. effective environmental protection into their plans and ensure that investment in environmental protection; $\mathrm{B}$. improve environmental protection legal system, establish a new environmental order of the socialist market economic system, recognizing that the market economy is the legal economy.

\section{ACKNOWLEDGMENT}

This study was supported by National Social Science Fund (15BGL139), the Key Technology Research and Development Program of Hubei Province (No.2014BCB041, 2015BDF050), Hubei Provincial Higher Education Research Project (2014-S-02).

\section{REFERENCES}

[1] Song Wenhua, Li Hongliu, Luo Yanhe, Zhao Jinglei. "Trend Analysis on Coordination Between Resource Environment and Economy in Xiqing District Under Ecological Civilization Construction." Environmental Science and Management, vol. 39, 2014, pp.140-143.

[2] Wang Xia. "Comparison Research on Economic Efficiency of Cities under the Restriction of Resources and Environment---Based on the comparison of 14 cities in central and Yangtze river economic belt." Science Technology and Industry, vol. 9, 2015, pp.45-51.

[3] Grossman G, Krueger A. "Economic environment and the economic growth," Quarterly Journal of Economics, vol.110, May 1995, pp. 353-377.

[4] $\mathrm{Ru} \mathrm{X,} \mathrm{Chen} \mathrm{S,} \mathrm{Dong} \mathrm{H.} \mathrm{"An} \mathrm{empirical} \mathrm{study} \mathrm{on} \mathrm{relationship}$ between economic growth and carbon emissions based on decoupling theory," Journal of Sustainable Development, vol. 5, 2012, pp.43.

[5] Fang Chuanglin, Bao Chao, Qiao Biao. "Urbanization process and eco - environmental effects," Science Press, 2008.

[6] Liu Yaobin. "Urbanization and Ecological Environment Coupling Mechanism and Regulation," Economic Science Press, 2007

[7] Tian L, Chen J, Yu S X. "Coupled dynamics of urban landscape pattern and socioeconomic drivers in Shenzhen, China," Landscape ecology, vol. 29, pp. 715-727.

[8] Zhao Anzhou, Li Yingjun, Wei Haiyan. "Evolutional Analysis of Coupling Between Urbanization and Resource-environment in Shaanxi," Research of Agricultural Modernization, vol. 32, 2011, pp. 725-729.

[9] Ma Kai, Pan Huanxue, Wang Zhongping. "The coupling relationship between urbanization and urban resource pressures in Beijing," Journal of Arid Land Resources and Environment, vol. 27, 2013, pp. 35-40.

[10] De Bruyn S M, Opschoor J B. "Developments in the throughputin-come relationship: Theoretical and empirical observations," Ecological Economics, vol. 20, 1997, pp. 255-268.

[11] Vehmas J, Kaivo-oja J, Luukkanen J. "Global trends of linking environmental stress and economic growth," Turku:Finland Futures Research Centre, 2003, pp. 6-9.

[12] Climent F, Pardo A. "Decoupling factors on the energy-output linkage: The Spanish case," Energy Policy, vol. 35, 2007, pp. 522 528.

[13] Tapio P. "Towards a theory of decoupling: Degrees of decoupling in the EU and the case of road traffic in finland between 1970 and 2001, " Transport Policy, vol. 12, 2005, pp. 137-151. 